Perspective

\title{
Understanding the Regulation of Transcription in Mental Illness
}

Sean J. O'Sullivan ${ }^{1,2, *}$

1. Daniel Baugh Institute for Functional Genomics and Computational Biology, Department of Pathology, Anatomy and Cell Biology, Thomas Jefferson University, Philadelphia, PA, United State; E-Mail: sjo003@stanford.edu

2. Brain Stimulation Lab, Stanford University, Stanford, CA., United States

* Correspondence: Sean J. O’Sullivan; E-Mail: sjo003@stanford.edu

Academic Editors: Jean-Baptiste Vannier and Rosa Maria Porreca

Special Issue: $\underline{\text { Chromatin Remodeling }}$

OBM Genetics

2021, volume 5 , issue 4

doi:10.21926/obm.genet. 2104143
Received: June 17, 2021

Accepted: October 25, 2021

Published: November 17, 2021

\begin{abstract}
Advances in clinical psychiatry have been less than hoped for relative to the achievements in neuroscience. However, developments in neuromodulation and psychedelic therapy are promising. The efficacy of such treatments and canonical pharmacotherapies benefit from genetics and personalized medicine. Moreover, recent studies on the perturbation of transcription, including chromatin remodeling, in mental illness emphasized the importance of single-cell qPCR as an investigatory method that bolstered psychiatry. This technique demonstrated chromatin remodeling as a biomarker for addiction and the underlying mechanism of depression. If personalized medicine, along with canonical and newer therapies, can mediate and regulate transcription, epidemics in depression and addiction can be mitigated. This motivates investigators to continue to use single-cell transcription measures in models of mental illness for translational medicine.
\end{abstract}

\section{Keywords}

Chromatin remodeling; molecular psychiatry; transcription; personalized medicine; addiction; depression conditions of the Creative Commons by Attribution License, which permits unrestricted use, distribution, and reproduction in any medium or format, provided the original work is correctly cited. 


\section{Introduction}

Mental illness remains a formidable challenge for Western medicine. Despite major advances in the neurosciences, rates of depression, anxiety, addiction, and suicide have increased in recent decades [1-3]. Though many studies have contributed considerably to psychiatry, therapeutic translation has been rare in recent decades [4-6]. However, current developments suggest that novel approaches and treatments can bolster psychiatry and contribute to solving the mental health crisis. Neuromodulation and psychedelic therapies, combined with advances in neuroimaging, have proven to be efficacious as treatments and investigatory tools [7, 8]. Futher, widespread use of these therapeutics is possible $[9,10]$. Moreover, such novel treatments are guided by a paradigm shift in genetics, epigenetics, and personalized medicine.

Canonical psychiatric pharmacotherapies and newer treatments benefit from the personalized medicine paradigm. Choosing patients more likely to respond to one selective serotonin reuptake inhibitor (SSRI) vs. another, based on polymorphisms in liver enzymes, can lead to considerable progress [11]. Similarly, choosing patients more likely to respond to specific protocols of transcranial magnetic stimulation (TMS) vs. cognitive behavioral therapy (CBT) can also lead to significant progress $[12,13]$. However, genome-wide association studies (GWAS) conducted to search for polymorphisms for explaining psychiatric diagnoses have disappointed many as the effect size is often small, and positive findings explain the effects in only a small proportion of the patients with the disease $[14,15]$. This has led investigators of mental illness to focus on transcription and its regulation.

Measuring transcription and its regulation and using the insights gained to impact patient care presents unique challenges. For example, non-rhythmic brain regions have profound transcriptional variation associated with the circadian rhythm [16]. Additionally, stochastic patterns of transcription require investigators to account for such dynamics [17]. The biological scale at which such transcription is measured also influences how such insights can be translated into clinical practice. Tissue-level findings group neurons, glia, and endothelial cells among other brain cell types into one bundle. Studies at this scale provide an understanding of large trends within a brain nucleus or region but may omit critical single-cell findings. A higher resolution provides distinct insights that may better explain clinical observations or inform precision treatments. This occurs in chromatin remodeling associated with substance addiction and models of depression [18]. Neighboring neurons with indistinguishable morphology can vary in cell ploidy and show transcriptional heterogeneity $[19,20]$.

These factors motivated single-cell transcriptomic studies with a systems biology approach [21, 22]. Various platforms have been developed in recent years to conduct these studies, and such techniques have been effective. However, many of these methods pose statistical and reproducibility challenges $[23,24]$. Polymerase chain reaction (PCR), conversely, is an older method that is very sensitive and specific and can be used to study transcription and its regulation, including chromatin remodeling. Though PCR is not as high-throughput as more recent platforms, such as microarray and RNA-seq, it remains a reliable tool that is often used to validate the findings of newer methods. 
Microfluidic real-time quantitative PCR (RT-qPCR) platforms such as Biomark ${ }^{\mathrm{TM}}$ are capable of generating large datasets with high accuracy at relatively lost cost. Moreover, this technique can be combined with other techniques to understand the regulation of transcription at the single-cell level. Our group combined microfluidic RT-qPCR with laser capture microdissection (LCM) to investigate glial-neuronal signaling in alcohol and opioid withdrawal [25-27]. LCM can be used to analyze sections of tissue or single cells and has advantages over single-cell selection techniques, such as fluorescence-activated cell sorting (FACS), as LCM can localize a single cell and its relation to the surrounding cells and their transcriptomes with high anatomic specificity [28]. Additionally, qPCR can be used to determine epigenetic regulation of transcription, such as chromatin remodeling, which is an emerging pathological source of mental illness [18].

Addiction to substances is a growing behavioral disease. Individual suffering, along with socioeconomic and politico-cultural costs, motivates scientists and physicians to conceive novel and efficacious treatments. Recent studies suggested that the persistent behaviors defining substance addiction are associated with chromatin remodeling $[18,29]$. GWAS studies have found polymorphisms in cholinergic receptor genes, the D2-dopamine receptor, and a protein (ANNK1) that predispose individuals to such behaviors [15], but these genetic predispositions do not explain most of the addiction epidemic. Epigenetic processes that influence transcriptional regulation, such as DNA methylation and histone modification, probably play a much larger role in addiction behaviors. Therefore, understanding the mechanisms of chromatin remodeling in addiction might benefit many individuals who suffer from this disease [30].

In a human post-mortem study, Bannon et al. (2014) [31] analyzed gene expression in cocaineaddicted patients and age-matched controls in single dopamine neurons. Findings from a microarray platform were confirmed with qPCR that showed differential expression in $\sim 90$ gene transcripts, mostly involved in transcription regulation and skewed toward chromatin remodeling. They concluded that such changes might constitute biomarkers of cocaine addiction. The midbrain region that these dopamine neurons project to, the nucleus accumbens, also demonstrated chromatin remodeling. Hyperacetylation and hypomethylation of histone proteins in stimulant addiction is the general trend, which increases the transcription rate across the genome [30]. However, investigators have also identified specific genes in which deacetylation and hypermethylation are consistently observed, suggesting a complex mechanism that might involve single-cell precision as well [32]. Recent reviews have discussed such findings in detail [33-35].

Chromatin remodeling is also central to the pathophysiology of depression [36]. Strikingly, the same chromatin remodeling features observed in addiction have been found in animal models of depression, suggesting that these same mechanisms underlie mental illness generally [32]. Rodents chronically exposed to stress can develop social defeatism, which is dependent on histone acetylation and methylation [37]. Moreover, a potential peripheral biomarker of depression, acetylL-carnitine (LAC), has emerged from this study [38]. LAC is a mitochondrial metabolite that donates its acetyl group to multiple proteins and has rapid antidepressant-like effects via histone acetyltransferase (HAT) activation [39]. Specifically, LAC acts on P300, which regulates the expression of multiple genes, including the metabotropic glutamate receptor-2 (mGlu2)-a protein central to synaptic plasticity. LAC also upregulates mGlu2 expression via activation of the transcription factor NF-KB [40]. The study not only demonstrated the complexity of body-mind pathology but also suggested a potential treatment, LAC supplementation, to ameliorate the underlying mechanisms causing the disease. 
The role of chromatin remodeling in depression is especially relevant to novel treatments for depression such as TMS [41, 42], psychedelics [43], and ketamine [44]. Precision psychiatry, which promises the selection of specific brain stimulation protocols or psychedelic-assisted therapies for specific patients based on symptoms, biomarkers, genetics, and various other parameters, might improve the efficacy of clinical tools used for mental illness by facilitating chromatin remodeling in the relevant neuronal populations leading to enduring anti-depressive effects. Moreover, a single treatment modality that remodels chromatin might benefit multiple psychiatric conditions. TMS, for example, has demonstrated considerable chromatin remodeling properties and is FDA approved for treatment-resistant depression, obsessive-compulsive disorder, and nicotine-use disorder [42].

Substantial improvements in clinical psychiatry have been sparse over the past few decades [4, 5]. Moreover, a recent increase in the cases of mental illness has motivated investigators and clinicians to search for novel and efficacious treatments [1-3]. Innovation in genetic sequencing and personalized medicine is promising [12]. Another promising technique is the use of single-cell transcriptomics combined with systems biology to understand the pathophysiology underlying these diseases [21]. Finally, advances in neuroimaging have facilitated precision psychiatry by phenotyping depression with objective markers that can guide individualized treatment regimens for that depression 'biotype' [7]. Chromatin remodeling plays a central role in the underlying neuropsychopathology of the enduring behaviors of common mental illnesses, such as substance addiction and depression. Further investigation might yield a better understanding of these biological processes, leading to novel applications of new therapies for treating patients with these diseases.

\section{Author Contributions}

The author did all the research work of this study.

\section{Competing Interests}

The author has declared that no competing interests exist.

\section{References}

1. Substance abuse and mental health services administration. Key substance use and mental health indicators in the United States: Results from the 2019 national survey on drug use and health. Rockville: SAMHSA; 2020.

2. Merikangas KR, He JP, Burstein M, Swanson A, Avenevoli S, Cui L, et al. Lifetime prevalence of mental disorders in U.S. adolescents: Results from the national comorbidity survey replicationadolescent supplement (NCS-A). J Am Acad Child Adolesc Psychiatry. 2010; 49: 980-989.

3. National Institute of Mental Health. Mental illness [Internet]. Bethesda: National Institute of Mental Health. Available from: https://www.nimh.nih.gov/health/statistics/mentalillness.shtml

4. Holmes EA, Craske MG, Graybiel AM. Psychological treatments: A call for mental-health science. Nature. 2014; 511: 287-289. 
5. Holmes EA, Ghaderi A, Harmer CJ, Ramchandani PG, Cuijpers P, Morrison AP, et al. The lancet psychiatry commission on psychological treatments research in tomorrow's science. Lancet Psychiatry. 2018; 5: 237-286.

6. Ford CL, Young LJ. Translational opportunities for circuit-based social neuroscience: Advancing 21st century psychiatry. Curr Opin Neurobiol. 2021; 68: 1-8.

7. Drysdale AT, Grosenick L, Downar J, Dunlop K, Mansouri F, Meng Y, et al. Resting-state connectivity biomarkers define neurophysiological subtypes of depression. Nat Med. 2017; 23: 28-38.

8. Carhart-Harris RL, Leech R, Hellyer PJ, Shanahan M, Feilding A, Tagliazucchi E, et al. The entropic brain: A theory of conscious states informed by neuroimaging research with psychedelic drugs. Front Hum Neurosci. 2014; 8: 20.

9. Johnson MW, Hendricks PS, Barrett FS, Griffiths RR. Classic psychedelics: An integrative review of epidemiology, therapeutics, mystical experience, and brain network function. Pharmacol Ther. 2019; 197: 83-102.

10. Sathappan AV, Luber BM, Lisanby SH. The dynamic duo: Combining noninvasive brain stimulation with cognitive interventions. Prog Neuro-Psychopharmacol Biol Psychiatry. 2019; 89: 347-360.

11. Ozomaro U, Wahlestedt C, Nemeroff CB. Personalized medicine in psychiatry: Problems and promises. BMC Med. 2013; 11: 132.

12. Chan S, Bota R. Personalized TMS: Role of RNA genotyping. Ment IIIn. 2019; 11: 8-15.

13. Andersson E, Crowley JJ, Lindefors N, Ljótsson B, Hedman-Lagerlöf E, Boberg J, et al. Genetics of response to cognitive behavior therapy in adults with major depression: A preliminary report. Mol Psychiatry. 2019; 24: 484-490.

14. Visscher PM, Brown MA, McCarthy MI, Yang J. Five years of GWAS discovery. Am J Hum Genet. 2012; 90: 7-24.

15. Bühler KM, Giné E, Echeverry-Alzate V, Calleja-Conde J, De Fonseca FR, Lõpez-Moreno JA. Common single nucleotide variants underlying drug addiction: More than a decade of research. Addict Biol. 2015; 20: 845-871.

16. Staehle MM, O'Sullivan S, Vadigepalli R, Kernan KF, Gonye GE, Ogunnaike BA, et al. Diurnal patterns of gene expression in the dorsal vagal complex and the central nucleus of the amygdala - non-rhythm-generating brain regions. Front Neurosci. 2020; 14: 375.

17. Harper CV., Finkenstädt B, Woodcock DJ, Friedrichsen S, Semprini S, Ashall L, et al. Dynamic analysis of stochastic transcription cycles. PLoS Biol. 2011; 9: e1000607.

18. Nestler EJ, Peña CJ, Kundakovic M, Mitchell A, Akbarian S. Epigenetic basis of mental illness. Neuroscientist. 2016; 22: 447-463.

19. Park J, Ogunnaike B, Schwaber J, Vadigepalli R. Identifying functional gene regulatory network phenotypes underlying single cell transcriptional variability. Prog Biophys Mol Biol. 2015; 117: 87-98.

20. Cai X, Evrony GD, Lehmann HS, Elhosary PC, Mehta BC, Poduri A, et al. Single-cell, genome-wide sequencing identifies clonal somatic copy-number variation in the human brain. Cell Rep. 2014; 8: $1280-1289$.

21. Geschwind DH, Konopka G. Neuroscience in the era of functional genomics and systems biology. Nature. 2009; 461: 908-915. 
22. Ideker T, Galitski T, Hood L. A new approach to decoding life: Systems biology. Annu Rev Genomics Hum Genet. 2001; 2: 343-372.

23. Saliba AE, Westermann AJ, Gorski SA, Vogel J. Single-cell RNA-seq: Advances and future challenges. Nucleic Acids Res. 2014; 42: 8845-8860.

24. SEQC Consortium. A comprehensive assessment of RNA-seq accuracy, reproducibility and information content by the sequencing quality control consortium. Nat Biotechnol. 2014; 32: 903-914.

25. O'Sullivan SJ, Reyes BAS, Vadigepalli R, Van Bockstaele EJ, Schwaber JS. Combining laser capture microdissection and microfluidic qpcr to analyze transcriptional profiles of single cells: $A$ systems biology approach to opioid dependence. J Vis Exp. 2020: e60612. doi: 10.3791/60612.

26. O'Sullivan SJ, Malahias E, Park J, Srivastava A, Reyes B, Gorky J, et al. Single-cell glia and neuron gene expression in the central amygdala in opioid withdrawal suggests inflammation with correlated gut dysbiosis. Front Neurosci. 2019; 13: 665.

27. O'Sullivan SJ, Mclntosh-Clarke D, Park J, Vadigepalli R, Schwaber JS. Single neuronal and glial gene expression in the nucleus tractus solitarius in an alcohol withdrawal time series reveals novel cellular phenotypes and networks. Res Square. 2021: 1-22. doi: 10.21203/rs.3.rs452767/v1.

28. Achanta S, Vadigepalli R. Single cell high-throughput qRT-PCR protocol. Res Square. 2021. doi: 10.21203/rs.3.pex-919/v1.

29. Robison AJ, Nestler EJ. Transcriptional and epigenetic mechanisms of addiction. Nat Rev Neurosci. 2011; 12: 623-637.

30. Walker DM, Cates HM, Heller EA, Nestler EJ. Regulation of chromatin states by drugs of abuse. Curr Opin Neurobiol. 2015; 30: 112-121.

31. Bannon MJ, Johnson MM, Michelhaugh SK, Hartley ZJ, Halter SD, David JA, et al. A molecular profile of cocaine abuse includes the differential expression of genes that regulate transcription, chromatin, and dopamine cell phenotype. Neuropsychopharmacol. 2014; 39: 2191-2199.

32. Heller EA, Cates HM, Peña CJ, Sun H, Shao N, Feng J, et al. Locus-specific epigenetic remodeling controls addiction - and depression-related behaviors. Nat Neurosci. 2014; 17: 1720-1727.

33. Browne CJ, Godino A, Salery M, Nestler EJ. Epigenetic mechanisms of opioid addiction. Biol Psychiatry. 2020; 87: 22-33.

34. Longley MJ, Lee J, Jung J, Lohoff FW. Epigenetics of alcohol use disorder-A review of recent advances in DNA methylation profiling. Addict Biol. 2021; 26: e13006.

35. Maldonado R, Calvé P, García-Blanco A, Domingo-Rodriguez L, Senabre E, Martín-García E. Genomics and epigenomics of addiction. Am J Med Genet Part B Neuropsychiatr Genet. 2021; 186: 128-139.

36. Nestler EJ. Epigenetic mechanisms of depression. JAMA Psychiatry. 2014; 71: 454-456.

37. Nasca C, Menard C, Hodes G, Bigio B, Pena C, Lorsch Z, et al. Multidimensional Predictors of Susceptibility and Resilience to Social Defeat Stress. Biol Psychiat. 2019; 86: 483-491.

38. Nasca C, Bigio B, Lee FS, Young SP, Kautz MM, Albright A, et al. Acetyl-I-carnitine deficiency in patients with major depressive disorder. Proc Natl Acad Sci. 2018; 115: 8627-8632.

39. Nasca C, Xenos D, Barone Y, Caruso A, Scaccianoce S, Matrisciano F, et al. L-acetylcarnitine causes rapid antidepressant effects through the epigenetic induction of $\mathrm{mGlu2}$ receptors. Proc Natl Acad Sci. 2013; 110: 4804-4809. 
40. Cuccurazzu B, Bortolotto V, Valente MM, Ubezio F, Koverech F, Canonico PL, et al. Upregulation of mGlu2 receptors via NF-kB p65 acetylation is involved in the proneurogenic and antidepressant effects of acetyl-I-carnitine. Neuropsychopharmacol. 2013; 38: 2220-2230.

41. Etiévant A, Manta S, Latapy C, Magno LA, Fecteau S, Beaulieu J-M. Repetitive transcranial magnetic stimulation induces long-lasting changes in protein expression and histone acetylation. Sci Reports. 2015; 5: 16873.

42. Etiévant A, Manta S, Latapy CV, Magno LA, Chauvette S, Timofeev I, et al. Repetitive transcranial magnetic stimulation induces chromatin remodeling. Brain Stimul. 2015; 8: 323.

43. Inserra A. Hypothesis: The psychedelic ayahuasca heals traumatic memories via a sigma 1 receptor-mediated epigenetic-mnemonic process. Front Pharmacol. 2018; 9: 330.

44. Choi M, Lee SH, Wang SE, Ko SY, Song M, Choi JS, et al. Ketamine produces antidepressant-like effects through phosphorylation-dependent nuclear export of histone deacetylase 5 (HDAC5) in rats. Proc Natl Acad Sci. 2015 ;112: 15755-15760.

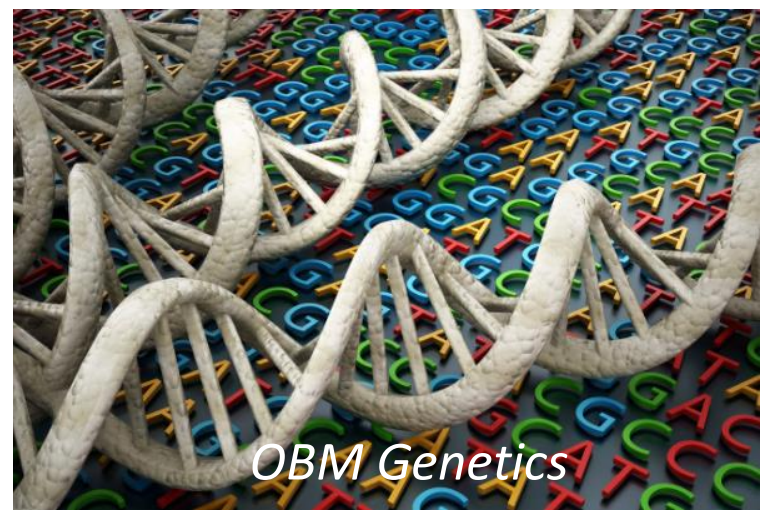

Enjoy OBM Genetics by:

1. Submitting a manuscript

2. Joining in volunteer reviewer bank

3. Joining Editorial Board

4. Guest editing a special issue

For more details, please visit:

http://www.lidsen.com/journals/genetics 